\title{
Revisão de Trichonius Bates (Coleoptera, Cerambycidae, Lamiinae)
}

\author{
Marcela L. Monné ${ }^{\&}$ José Ricardo M. Mermudes ${ }^{2}$
}

\begin{abstract}
${ }^{1}$ Museu Nacional, Universidade Federal do Rio de Janeiro. Quinta da Boa Vista, São Cristovão, 20940-040 Rio de Janeiro-RJ, Brasil. ${ }^{2}$ Departamento de Zoologia. Universidade do Estado do Rio de Janeiro. Rua São Francisco Xavier, 524, Maracanã, 20550-900 Rio de Janeiro, Brasil.
\end{abstract}

\begin{abstract}
Revision of Trichonius Bates (Coleoptera, Cerambycidae, Lamiinae). The genus Trichonius Bates, 1864 and its species are redescribed. Eight species are recognized, of which five are described as new: Trichonius minimus sp. nov., T. bellus sp. nov. and T. griseus sp. nov. from French Guiana and Brazil; T. affinis sp. nov. (Mato Grosso), and T. atlanticus sp. nov. (Bahia, Minas Gerais) from Brazil. All the species are illustrated and a key to species provided.
\end{abstract}

KEYWORDS. Acanthocinini; Neotropical; new species; taxonomy.

RESUMO. Revisão de Trichonius Bates (Coleoptera, Cerambycidae, Lamiinae). O gênero Trichonius Bates, 1864 e suas espécies são redescritos. Oito espécies são reconhecidas, das quais cinco novas são descritas: Trichonius minimus sp. nov., T. bellus sp. nov. e T. griseus sp. nov. da Guiana Francesa e Brasil; T. affinis sp. nov. (Mato Grosso), e T. atlanticus sp. nov. (Bahia, Minas Gerais) do Brasil. São fornecidas chave para identificação das espécies e ilustrações.

PALAVRAS-CHAVE. Acanthocinini; Neotropical; espécies novas; taxonomia.

Bates (1864) propôs Trichonius e descreveu três espécies que ocorrem na região Amazônica: T. fasciatus (Pará), T. picticollis (Amazonas) e T. quadrivittatus (Amazonas). Thomson (1864) designou Trichonius quadrivittatus como espécie-tipo do gênero.

O estudo dos holótipos das espécies de Bates no Muséum National d'Histoire Naturelle, Paris, permitiu reconhecer cinco novas espécies, que são acrescidas ao gênero. Neste trabalho, o gênero e suas espécies são redescritos e são fornecidas chave para identificação das espécies e ilustrações.

O material examinado pertence ao Muséum National d'Histoire Naturelle, Paris (MNHN) e ao Museu Nacional, Universidade Federal do Rio de Janeiro, Rio de Janeiro (MNRJ).

\section{Trichonius Bates, 1864}

Trichonius Bates, 1864: 52; Thomson, 1864: 323, 355; Lacordaire, 1872: 784; Monné, 2005: 140 (cat.).

Espécie-tipo. Trichonius quadrivittatus Bates, 1864 (designação de Thomson, 1864: 323).

Cabeça com raras cerdas eretas; fronte larga e vertical; lobos oculares inferiores alongados, cerca de quatro vezes a largura do lobo ocular superior. Antenas ultrapassam os ápices elitrais nos dois sexos. Pedicelo e antenômeros III-X com cerdas esparsas, eretas e pretas.

Protórax mais largo que longo; aos lados com uma evidente projeção látero-basal. Pronoto sem tubérculos e, na margem posterior, com fileira de pontos moderadamente grossos. Cavidades procoxais fechadas atrás; cavidades mesocoxais fechadas aos lados. Processos prosternal e mesosternal alargados. Élitros cerca de três a quatro vezes mais longos que o protórax; com abundantes cerdas suberetas, pretas e alongadas no terço apical; região circumescutelar intumescida; sem carenas laterais, grânulos ou crista basal. Úmeros arredondados. Escutelo com a margem apical arredondada. Pro- e mesocoxas arredondadas, ligeiramente proeminentes. Fêmures clavados, a clava menos evidente nos metafêmures. Tíbias cilíndricas e com abundantes cerdas eretas; mesotíbias com sulco; esporões curtos e subiguais.

Esternito I 1/3 mais longo que o II; II-V subiguais em comprimento. Nas fêmeas, os esternito e tergito $\mathrm{V}$, apresentam as margens apicais arredondadas e o esternito $\mathrm{V}$ duas vezes mais longo que o anterior; nos machos, variável.

Discussão. Bates (1864) considerou Trichonius semelhante a Probatius White, 1855 (=Alcidion Sturm, 1843) e Oxathres Bates, 1864 pela forma do protórax e pelas cerdas no corpo e o diferenciou pelos esternito e tergito $\mathrm{V}$ com a margem apical arredondada. Lacordaire (1872) aproximou Trichonius de Oedopeza Audinet-Serville, 1833, que difere por apresentar crista basal nos élitros. Atualmente, entre os 149 gêneros neotropicais da tribo Acanthocinini (Monné 2005), Trichonius assemelha-se também a Brevoxathres Gilmour, 1959, Palame Bates, 1864, Piezochaerus Melzer, 1932 e Tenthras Thomson, 1864 por apresentarem em comum o protórax com tubérculo lateral situado no terço posterior, o pronoto sem tubérculos, os élitros com cerdas suberetas, sem carena lateral, sem crista basal ou grânulos e o metatarsômero I igual ou mais longo que II+III. Vale ressaltar que Trichonius é muito semelhante à Brevoxathres e difere pela característica citada por Bates (1864) sobre os esternito e tergito $\mathrm{V}$ com a margem apical arredondada nas fêmeas; em Brevoxathres as fêmeas apresentam os esternito e tergito $\mathrm{V}$ alongados e com ápices acuminados. Palame difere de Trichonius pelo antenômero VI, nos machos, com projeção espiniforme apical interna e tubérculos laterais do protórax diminutos; em Trichonius o antenômero VI, em 
ambos os sexos, é inerme e os tubérculos aos lados do protórax são evidentes. Em Piezochaerus, com maiores dimensões, o corpo tem aspecto deprimido dorso-ventralmente e o processo mesosternal é distintamente estreito; em Trichonius o corpo não tem aspecto deprimido e o processo mesosternal tem, pelo menos, 2/3 da largura da mesocoxa. Em Tenthras as antenas são mais curtas que o corpo em ambos os sexos e o esporão das metatíbias é distintamente desenvolvido; em Trichonius as antenas são mais longas que o corpo e os esporões das metatíbias são curtos e subiguais.

As espécies de Trichonius são morfologicamente muito semelhantes, diferindo principalmente pela pubescência que recobre a região dorsal do corpo e pelos caracteres descritos na chave.

Chave para as espécies de Trichonius

1. Escapo e fêmures com cerdas longas; pronoto e élitros com pubescência principalmente acinzentada. Guiana Francesa, Brasil (Amazonas, Pará) (Fig. 5) ...........

T. griseus sp. nov.

Escapo e fêmures sem cerdas ou, quando presentes, apenas nos metafêmures; pubescência de outra cor

. .2

2(1). Pronoto com manchas de pubescência branca; antenômeros III-XI distintamente decrescentes em comprimento; antenas alcançam os ápices elitrais no antenômero VIII. Brasil (Amazonas) (Fig. 7) .

T. picticollis Bates

Pronoto sem manchas brancas; antenômeros III-XI gradualmente decrescentes; antenas alcançam os ápices elitrais no antenômero $\mathrm{V}$ ou VI ... 3

3(2). Região circumescutelar com mancha de pubescência castanho-escura ........................................................... 4

Região circumescutelar sem mancha de pubescência castanho-escura

4(3). Antenômeros III-XI unicolores, castanho-escuros, exceto metade anterior do V, amarela. Guiana Francesa, Brasil (Amazonas, Pará) (Fig. 3) ........ T. bellus sp. nov.

Antenômeros III-XI bicolores, castanho-escuros com terços basais amarelados

5(4). Lados do protórax com projeção pouco aparente, próxima à margem posterior; élitros com uma faixa pósescutelar no terço basal e manchas arredondadas e confluentes de pubescência castanho-escura; escutelo com pubescência castanho-clara. Brasil (Mato Grosso) (Fig. 1)

T. affinis sp. nov.

Lados do protórax com pequena projeção aguçada, próxima à margem posterior; élitros com uma mancha mediana basal, que inclui o escutelo, pequenas manchas arredondadas e faixa transversal no terço posterior, castanho-escuras. Brasil (Bahia, Minas Gerais) (Fig. 2). T. atlanticus sp. nov.
6(3). Pronoto com pubescência amarelada e duas faixas longitudinais castanho-escuras; élitros com estreita faixa transversal, no terço apical, de pubescência castanho-escura. Brasil (Amazonas) (Fig. 4) ............

T. fasciatus Bates

Pronoto com pubescência esbranquiçada ou amarelada e quatro faixas longitudinais castanho-escuras; élitros sem faixa transversal de pubescência castanho-escura

. .7

7(6). Protórax transverso, duas vezes mais largo que longo; dorso dos metafêmures com cerdas. Brasil (Amazonas, Mato Grosso) (Fig. 8) ............ T. quadrivittatus Bates

Protórax trapezoidal, 1/3 mais longo que largo; metafêmures sem cerdas. Guiana Francesa, Brasil (Amazonas, Rondônia, Mato Grosso) (Fig. 6) ... T. minimus sp. nov.

\section{Trichonius affinis sp. nov.}

(Fig. 1)

Tegumento de maneira geral castanho, recoberto de pubescência esbranquiçada. Cabeça com lobos oculares superiores tão distantes entre si quanto a largura de um lobo. Tubérculos anteníferos pouco proeminentes. Antenas com fina pubescência amarelada, ultrapassam os ápices elitrais no antenômero V; escapo tão longo quanto o antenômero III; III$\mathrm{XI}$ subiguais em comprimento e bicolores, castanho-escuros com o terço basal amarelado.

Lados do protórax ligeiramente divergentes para a margem posterior; projeção látero-basal aguçada, pouco aparente. Pronoto com pubescência esbranquiçada e quatro faixas longitudinais castanhas, somente as medianas alcançam as margens. Processo prosternal cerca de 1/3 da largura da procoxa. Processo mesosternal ligeiramente mais estreito que a mesocoxa. Élitros com pubescência esbranquiçada exceto uma faixa pós-escutelar no terço basal e manchas arredondadas, confluentes de pubescência castanho-escura; ápices obliquamente truncados. Escutelo com pubescência castanha.

Pernas com pubescência esbranquiçada exceto terço basal e apical das tíbias, castanho-escuros. Fêmures sem cerdas no dorso. Protarsômero I cerca de 2/3 do comprimento do II+III; mesotarsômero I tão longo quanto II+III; metatarsômero I 1/3 mais longo que II+III. Esternito e tergito V, nos machos, com as margens apicais truncadas.

Dimensões, em mm, macho/fêmea. Comprimento total, 4,6/ 5,5; comprimento do protórax, 0,8/1,2; maior largura do protórax, 1,2/1,7; comprimento do élitro, 3,2/3,8; largura umeral, 1,5/2,2.

Material-tipo. Holótipo macho, BRASIL, Mato Grosso: Sinop, X.1974, Alvarenga \& Roppa col. (MNRJ). Parátipo, mesmos dados do holótipo, fêmea, X.1975, Roppa \& Alvarenga col. (MNRJ).

Comentários. Trichonius affinis sp. nov. assemelha-se à $T$. quadrivittatus, $T$. fasciatus e $T$. minimus sp. nov. pelas faixas longitudinais de pubescência castanho-escura no pronoto e difere pela mancha pós-escutelar de pubescência castanhoescura. 


\section{Trichonius atlanticus sp. nov.}

(Fig. 2)

Tegumento de maneira geral castanho-escuro a preto. Cabeça com pubescência esbranquiçada; lobos oculares superiores tão distantes entre si quanto 1,5 vezes a largura de um lobo. Tubérculos anteníferos pouco proeminentes. Antenas com fina pubescência esbranquiçada, ultrapassam os ápices elitrais no antenômero VI; escapo tão longo quanto o antenômero III; III-XI subiguais em comprimento e bicolores, amarelados com o terço apical castanho-escuro.

Lados do protórax com pequena projeção aguçada, próxima à margem posterior. Pronoto com pubescência castanho-escura exceto duas pequenas manchas antemedianas e aos lados com pubescência esbranquiçada. Processo prosternal cerca da metade da largura da procoxa. Processo mesosternal tão largo quanto a mesocoxa. Élitros com pubescência esbranquiçada exceto uma mancha mediana basal que inclui o escutelo, pequenas manchas arredondadas em toda a superfície e larga faixa obliqua no terço posterior, castanho-escuras; ápices obliquamente chanfrados.

Pernas com pubescência esbranquiçada exceto terço apical das tíbias, castanho-escuro. Fêmures sem cerdas no dorso. Protarsômero I cerca de $2 / 3$ do comprimento do II+III; mesotarsômero I tão longo quanto II+III; metatarsômero I 1/3 mais longo que II+III. Esternito e tergito V, nos machos, com as margens apicais truncadas.

Dimensões, em mm, macho/fêmea. Comprimento total, 5,2/ 4,2; comprimento do protórax, 0,9/0,6; maior largura do protórax, 1,5/1,2; comprimento do élitro, 3,1/3,0; largura umeral, 1,9/1,6.

Material-tipo. Holótipo macho, BRASIL, Bahia: Encruzilhada (Estrada Rio-Bahia, km 965, Motel da Divisa, 960 m), XI.1970, Seabra \& Roppa col. (MNRJ). Parátipos, mesmos dados do holótipo, macho, fêmea (MNRJ); macho, XI.1972 (MNRJ); fêmea, XI.1974 (MNRJ); Minas Gerais: Pedra Azul, 700 m, macho, fêmea, XI.1972, Seabra \& Oliveira col. (MNRJ).

Comentários. Entre as espécies de Trichonius, T. atlanticus sp. nov. é a única em que os élitros apresentam larga faixa oblíqua de pubescência castanho-escura no terço posterior e a primeira que ocorre na Mata Atlântica.

\section{Trichonius bellus sp. nov.} (Fig. 3)

Tegumento de maneira geral castanho; face ventral com pubescência esbranquiçada. Cabeça com pubescência amarelada exceto na região dorsal posterior, castanho-escura; lobos oculares superiores tão distantes entre si quanto o dobro da largura de um lobo. Tubérculos anteníferos pouco proeminentes. Antenas com fina pubescência amarelada e tegumento castanho-escuro exceto metade anterior do V, amarelo; ultrapassam os ápices elitrais no antenômero VI; escapo 1/3 mais curto que o antenômero III; III-V gradualmente decrescentes em comprimento, V-XI subiguais.

Lados do protórax divergentes para a margem posterior; projeção látero-basal larga e aguçada. Pronoto com pubescência castanho-escura e três faixas longitudinais amareladas que alcançam as margens, a mediana estreita e as laterais mais largas. Processo prosternal cerca de 1/3 da largura da procoxa. Processo mesosternal com $2 / 3$ da largura da mesocoxa. Élitros (Fig. 3) com faixa de pubescência cinzaazulada ornada de pequenas manchas de pubescência castanho-escura, que se inicia nos úmeros e acompanha a sutura até o ápice e é interrompida ou não, na região pósmediana, por faixa lateral castanho-escura ornada por pequenas manchas amarelas; mancha circumescutelar de pubescência castanho-escura bordeada de pubescência amarela; ápices sinuosos e com ângulo externo projetado. Escutelo com pubescência castanho-escura.

Pernas com pubescência esbranquiçada exceto terço basal e apical das tíbias, castanho-escuros. Fêmures alaranjados e sem cerdas no dorso. Tíbias e tarsos castanhos. Protarsômero I ligeiramente mais longo que o II; mesotarsômero I tão longo quanto II+III; metatarsômero I ligeiramente mais longo que II+III. Esternito e tergito V, nos machos, com as margens apicais arredondadas.

Dimensões, em mm, macho/fêmea. Comprimento total, 7,2/ 6,3; comprimento do protórax, 1,3/0,9; maior largura do protórax, 2,3/1,9; comprimento do élitro, 4,8/4,2; largura umeral, 2,5/2,2.

Material-tipo. Holótipo macho, BRASIL, Pará: Jacareacanga, macho, XII.1968, M. Alvarenga col. (MNRJ). Parátipos: GUIANA FRANCESA, Montagne des Singes, pk 7, macho, 04.V.1984, G.Tavakilian col. (MNHN); RN 1, pk 14, 1 macho, 1 fêmea ("obtenu par élevage sur tronc nourricier"), 26.XII.1984, P. Sarry col. (MNHN); Saül (Eaux Claires), fêmea (“à vue de jour"), 18.II.1996, A. Berkov col. (MNHN); (Mont La Fumée), fêmea, 27.III.1983 (battage), G.Tavakilian col. (MNHN); Route forestière de Belizon, pk 1, fêmea, 31.I.1995 (battage), E.Giesbert col. (MNHN). BRASIL, Amazonas: Manaus, 2 fêmeas, VI.1972, Roppa \& Oliveira col. (MNRJ). Pará: Jacareacanga, 3 machos, XII.1968 (MNRJ); 6 machos, I.1969, F. R. Barbosa col. (MNRJ); 2 machos, 2 fêmeas, II.1969 (MNRJ); 3 machos, III.1969 (MNRJ); fêmea, IV.1969, F. R. Barbosa col. (MNRJ); macho, fêmea, X.1969, F. R. Barbosa col. (MNRJ); macho, 3 fêmeas, I.1969, F. R. Barbosa col. (MNRJ); Tucuruí, 5 machos, I.1980, B. Silva col. (MNRJ)

Comentários. Trichonius bellus sp. nov. difere das demais espécies de Trichonius pelos antenômeros unicolores castanhos, exceto a metade anterior do V, com tegumento amarelo e pelos élitros com faixa de pubescência cinza-azulada ornada de pequenas manchas de pubescência castanhoescura, que se inicia nos úmeros e acompanha a sutura até o ápice.

\section{Trichonius fasciatus Bates, 1864}

(Fig. 4)

Trichonius fasciatus Bates, 1864: 53; Tippmann, 1960: 196; Monné, 2005: 140 .

Macho. Tegumento de maneira geral castanho-escuro a avermelhado, revestido de pubescência esbranquiçada ou amarelada. Cabeça com lobos oculares superiores distantes entre si cerca de 1,5 vezes a largura de um lobo. Tubérculos anteníferos pouco proeminentes. Antenas ultrapassam os 
ápices elitrais no antenômero VI; escapo tão longo quanto o antenômero III; III-XI ligeiramente decrescentes em comprimento; IV-XI bicolores, castanho-escuros com terço basal castanho-claro.

Lados do protórax com uma projeção romba no ângulo posterior, direcionada para os úmeros. Pronoto com pubescência amarelada e duas faixas longitudinais, sinuosas e castanho-escuras, que alcançam as margens. Prosterno com pubescência amarelada; processo prosternal cerca de $2 / 3$ da largura da procoxa. Mesosterno com pubescência amarelada; processo mesosternal tão largo quanto a mesocoxa. Élitros com pubescência esbranquiçada com mancha lateral antemediana e faixa transversal no terço apical de pubescência castanho-escura; sutura elitral com pubescência esbranquiçada intercalada por pubescência castanho-escura, formando pequenas manchas; ápices obliquamente truncados. Escutelo com pubescência castanho-escura.

Metafêmures com três cerdas no dorso; pubescência esbranquiçada. Tíbias com pubescência castanho-escura exceto faixa ante-mediana esbranquiçada. Protarsômero I cerca de 2/3 do comprimento do II+III; mesotarsômero I tão longo quanto II+III; metatarsômero I 1/3 mais longo que II+III. Esternito e tergito $\mathrm{V}$ com a margem apical escavada.

Dimensões, em mm, macho. Comprimento total, 5,8; comprimento do protórax, 1,2; maior largura do protórax, 2,0; comprimento do élitro, 3,9; largura umeral, 2,2.

Material examinado. BRASIL, Pará: Santarém, holótipo macho (MNHN). Amazonas: Tefé, 4 machos, IX.1963, R. Carvalho col. (MNRJ).

Comentários. Espécie semelhante à T. quadrivittatus e difere por apresentar o pronoto com pubescência amarelada e duas faixas longitudinais castanho-escuras e os élitros com estreita faixa transversal, no terço apical, de pubescência castanho-escura. Em T. quadrivittatus o pronoto tem pubescência esbranquiçada ou amarelada e quatro faixas longitudinais castanho-escuras e os élitros não apresentam faixa transversal.

\section{Trichonius griseus sp. nov.} (Fig. 5)

Tegumento, de maneira geral, castanho-escuro com pubescência cinzento- esbranquiçada. Escapo, pedicelo, antenômeros III-X, élitros e pernas, com longas e abundantes cerdas pretas.

Cabeça com pubescência esbranquiçada; lobos oculares superiores tão distantes entre si quanto a largura de um lobo. Tubérculos anteníferos pouco proeminentes. Antenas com fina pubescência esbranquiçada, ultrapassam os ápices elitrais no antenômero VI; escapo tão longo quanto o antenômero III; III-XI subiguais em comprimento e I bicolores, castanhoescuros com o terço basal amarelado.

Lados do protórax com uma projeção aguçada no ângulo posterior, direcionada para os lados. Processo prosternal cerca da metade da largura da procoxa. Processo mesosternal ligeiramente mais largo que a mesocoxa.
Terço anterior dos élitros com uma larga faixa transversal, inteira ou interrompida no meio, de pubescência esbranquiçada e duas faixas estreitas, uma mediana e uma no terço posterior, de pubescência castanho-escura; sutura elitral com pubescência esbranquiçada intercalada por pubescência castanho-escura, mais evidente no terço apical; ápices obliquamente truncados. Escutelo com pubescência esbranquiçada.

Pernas com pubescência esbranquiçada exceto terço basal e apical das tíbias, castanho-escuros. Fêmures com três cerdas longas no dorso. Protarsômero I cerca de $2 / 3$ do comprimento do II+III; mesotarsômero I tão longo quanto II+III; metatarsômero I 1/3 mais longo que II+III.

Esternito e tergito V, nos machos, com as margens apicais chanfradas.

Dimensões, em mm, macho/fêmea. Comprimento total, 6,2/ 8,4; comprimento do protórax, 1,0/1,7; maior largura do protórax, 2,2/2,6; comprimento do élitro, 4,0/5,8; largura umeral, 2,5/2,8.

Material-tipo. Holótipo macho, BRASIL, Pará: Tucuruí, I.1980, B. Silva col. (MNRJ). Parátipos: GUIANA FRANCESA, Mont Grand Matoury (battage), fêmea, 16.I.1982, G.Tavakilian col. (MNHN); Piste du plateau des Mines, pk 2 (piégeage lumineux), macho, 27.I.1990, Baloup col. (MNHN). BRASIL, Amazonas: Fonte Boa, fêmea, X.1975, F. M. Oliveira col. (MNRJ). Pará: Tucuruí, fêmea, I.1980, B. Silva col. (MNRJ).

Comentários. Trichonius griseus sp. nov. difere das demais espécies pelo corpo e apêndices (inclusive escapo) com cerdas longas e abundantes, e pela pubescência geral do corpo acinzentada.

\section{Trichonius minimus sp. nov.} (Fig. 6)

Tegumento de maneira geral castanho-escuro ou castanhoavermelhado.

Cabeça com pubescência esbranquiçada; lobos oculares superiores cerca de 1,5 vezes tão distantes entre si quanto a largura de um lobo. Tubérculos anteníferos pouco proeminentes. Antenas com fina pubescência amarelada; ultrapassam os ápices elitrais no antenômero V ou VI; escapo tão longo quanto o antenômero III; III-V subiguais em comprimento, VI-XI ligeiramente decrescentes; III-VI bicolores, castanho-escuros com o terço basal amarelado.

Protórax com pubescência esbranquiçada; trapezoidal, com lados divergentes para margem posterior e com projeção aguçada no ângulo posterior dirigida para os úmeros. Pronoto com pubescência esbranquiçada e quatro faixas longitudinais castanho-escuras que alcançam as margens. Processo prosternal cerca de 1/3 da largura da procoxa. Mesosterno com pubescência amarelada; processo mesosternal ligeiramente mais estreito que a mesocoxa. Élitros com pubescência amarelada e manchas arredondadas, grandes e confluentes, de pubescência castanho-escura; ápices arredondados. Escutelo com pubescência castanho-escura.

Pernas com pubescência esbranquiçada. Metafêmures sem cerdas no dorso. Protarsômero I cerca de 2/3 do comprimento 

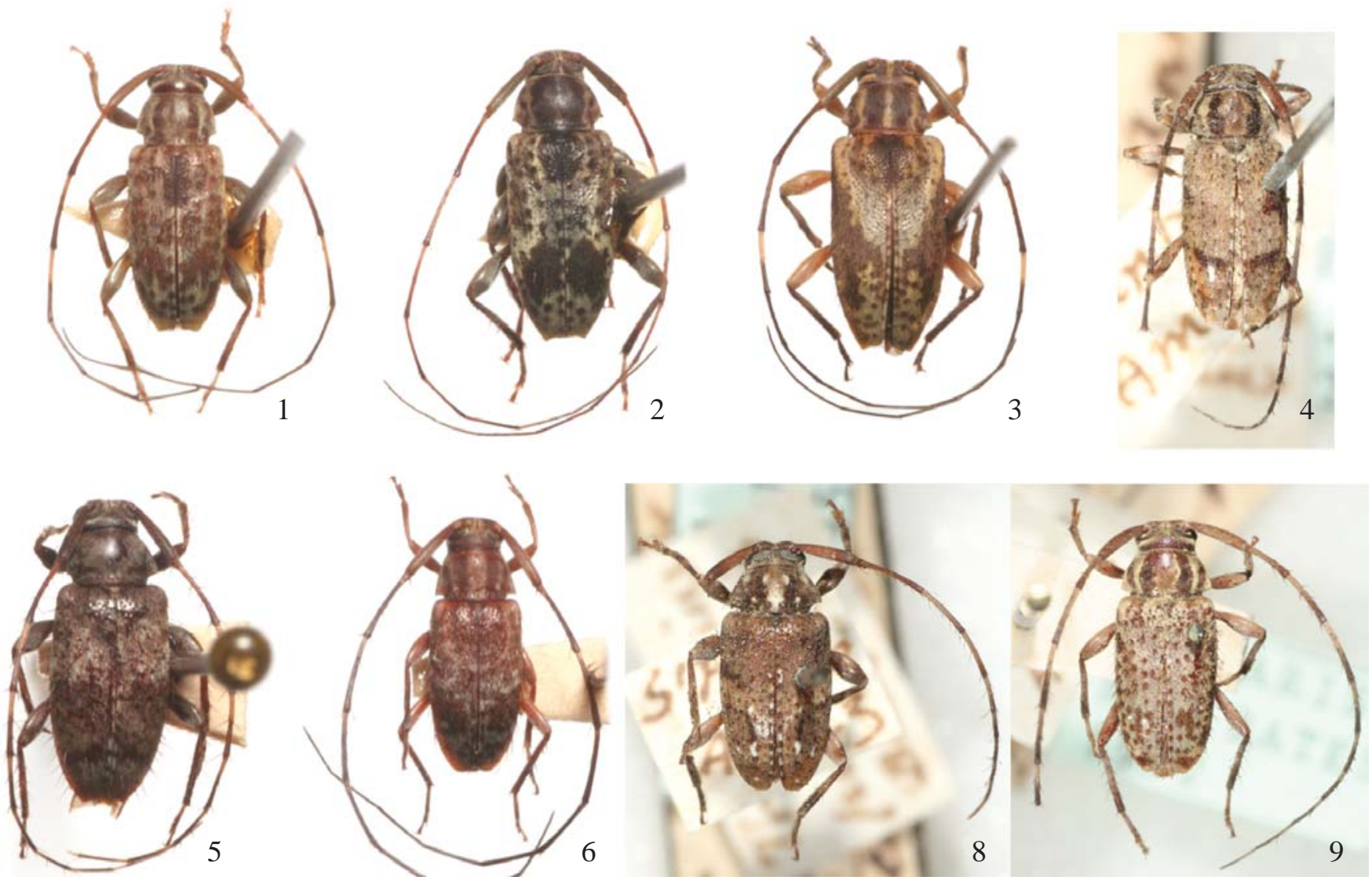

Figs 1-8. 1, Trichonius affinis sp. nov., holótipo macho; 2, T. atlanticus sp. nov., holótipo macho; 3, T. bellus sp. nov., holótipo macho; 4, Trichonius fasciatus Bates, holótipo macho (Pará, Brasil); 5, T. griseus sp. nov., holótipo macho; 6, T. minimus sp. nov., holótipo macho; 7, T. picticollis Bates, holótipo macho (Amazonas, Brasil); 8, T. quadrivittatus Bates, holótipo macho (Amazonas, Brasil).

do II+III; mesotarsômero I tão longo quanto II+III; metatarsômero I 1/3 mais longo que II+III. Machos com esternito $\mathrm{V}$ com a margem apical truncada e no tergito $\mathrm{V}$ arredondada.

Dimensões, em mm, macho/fêmea. Comprimento total, 4,5/ 6,2; comprimento do protórax, $0,7 / 1,0 ;$ maior largura do protórax, 1,4/2,0; comprimento do élitro, 3,3/4,2; largura umeral, 1,6/2,2.

Material-tipo. Holótipo macho, BRASIL, Mato Grosso: Sinop, X.1976, Roppa \& Alvarenga col. (MNRJ). Parátipos: GUIANA FRANCESA, Degrad 165, fêmea (battage), 10.III.1982, G. Tavakilian col. (MNHN); Crique Longi, fêmea, 01.XI.1993 (battage), F.T. Hovore col. (MNHN). BRASIL, Amazonas: Tefé, macho, 4 fêmeas, IX.1963, R. Carvalho col. (MNRJ). Rondônia: Marmelo, fêmea, XI.1962, W. Bokermann col. (MNRJ); Vilhena, macho, XI.1960 M. Alvarenga col. (MNRJ). Mato Grosso: Sinop, X.1974, macho, 2 fêmeas, Alvarenga \& Roppa col. (MNRJ).

Comentários. Trichonius minimus sp. nov.é a única espécie do gênero que apresenta o protórax com aspecto trapezoidal e manchas de pubescência castanho-escura, grandes e confluentes, nos élitros. Nas demais espécies o protórax tem aspecto transverso e as manchas elitrais são de menores dimensões, exceto em T. affinis sp. nov. em que também são grandes e confluentes.
Trichonius picticollis Bates, 1864

(Fig. 7)

Trichonius picticollis Bates, 1864: 53; Monné, 2005: 140.

Macho. Tegumento castanho ou avermelhado revestido e, de maneira geral, com pubescência amarelada.

Cabeça com raras cerdas eretas; lobos oculares superiores tão distantes entre si quanto a largura de um lobo. Tubérculos anteníferos proeminentes. Antenas ultrapassam os ápices elitrais no antenômeroVIII; escapo pouco mais curto que o antenômero III; III-XI distintamente decrescentes em comprimento; pedicelo e III-X com cerdas esparsas, eretas e pretas; IV-XI bicolores, castanho-claros com ápices escuros.

Protórax com uma projeção lateral romba no ângulo posterior, direcionada para os úmeros. Pronoto com pubescência castanha e sete manchas de pubescência branca pequenas exceto a mediana posterior, um pouco maior. Processo prosternal estreito, cerca da metade da largura da procoxa; processo mesosternal pelo menos tão largo quanto a mesocoxa. Élitros com pubescência castanha, com manchas irregulares castanho-escuras e brancas, concentradas nos $2 / 3$ apicais; $2 / 3$ apicais da sutura elitral com pubescência esbranquiçada intercalada por pubescência castanho-escura, formando pequenas manchas; ápices arredondados. Escutelo com pubescência castanho-escura. 
Metafêmures sem cerdas no dorso, pubescência esbranquiçada. Tíbias com pubescência esbranquiçada na metade basal e, na apical, castanho-escura. Pro- e mesotarsômeros I ligeiramente mais curtos que II+III; metatarsômero I subigual em comprimento ao II+III.

Esternito V truncado na margem apical. Tergito V com a margem arredondada.

Dimensões, em mm, macho. Comprimento total, 5,6; comprimento do protórax, 1,2; maior largura do protórax, 2,0; comprimento do élitro, 4,0; largura umeral, 2,2.

Material examinado. BRASIL, Amazonas: São Paulo de Olivença, holótipo macho (MNHN).

Comentários. Única espécie que apresenta distintas manchas de pubescência branca no pronoto e élitros, lobos oculares superiores tão distantes entre si quanto a largura de um lobo e tubérculos anteníferos proeminentes. Nas demais espécies a pubescência apresenta outro padrão, os lobos oculares superiores são mais distantes entre si e os tubérculos anteníferos não são proeminentes.

\section{Trichonius quadrivittatus Bates, 1864} (Fig. 8)

Trichonius quadrivittatus Bates, 1864: 53; Thomson, 1864: 323; Monné, 2005: 140.

Tegumento de maneira geral castanho-escuro ou avermelhado, revestido de pubescência esbranquiçada ou amarelada.

Cabeça com lobos oculares superiores distantes entre si cerca de 1,5 vezes a largura de um lobo. Tubérculos anteníferos pouco proeminentes. Antenas ultrapassam os ápices elitrais no antenômero VI; escapo pouco mais curto que o antenômero III; III-XI ligeiramente decrescentes em comprimento; IV-XI bicolores, castanho-escuros com a metade basal castanho-clara.

Lados do protórax com uma projeção romba no ângulo posterior, direcionada para os lados. Pronoto com pubescência amarelada e quatro faixas longitudinais castanho-escuras; duas medianas, longitudinais, sinuosas e alcançam as margens e duas externas curtas, oblíquas. Prosterno e mesosterno com pubescência amarelada; processo prosternal quase tão largo quanto a procoxa. Processo mesosternal pouco mais largo que a mesocoxa. Élitros com pubescência esbranquiçada e manchas arredondadas, algumas confluentes, de pubescência castanho-escura; ápices obliquamente truncados. Escutelo com pubescência castanho-escura.

Metafêmures com três cerdas no dorso; pubescência esbranquiçada. Tíbias com pubescência esbranquiçada na metade basal e, na apical, castanho-escura. Protarsômero I ligeiramente mais longo que II+III; mesotarsômero I 1/3 mais longo que II+III; metatarsômero I 1,5 mais longo que II+III.

Machos com a margem apical do esternito $\mathrm{V}$ truncada e no tergito $\mathrm{V}$, arredondada.

Dimensões, em mm, macho/fêmea.. Comprimento total, 5,8/ 6,8; comprimento do protórax, 1,1/1,3; maior largura do protórax, 2,0/2,3; comprimento do élitro, 3,9/4,8; largura umeral, 2,2/2,6.

Material examinado. BRASIL, Amazonas: Vila Nova [Parintins], holótipo macho (MNHN). Mato Grosso: Sinop, fêmea, macho, X.1976, Roppa \& Alvarenga col. (MNRJ).

Comentários. Trichonius quadrivittatus, T. fasciatus e $T$. griseus sp. nov. são as únicas com cerdas no dorso dos metafêmures. Ver comentários nessas espécies.

Agradecimentos. Ao CNPq pelo Auxílio Participação em Eventos Científicos (processo: 454591/2006-3). A Gerárd Tavakilian (MNHN) pelo empréstimo de material e a Miguel A. Monné (MNRJ) pelas sugestões ao manuscrito.

\section{REFERÊNCIAS}

Bates, H. W. 1864. Contributions to an insect fauna of the Amazon Valley. Coleoptera: Longicornes. The Annals and Magazine of Natural History 13: 43-56.

Lacordaire, J. T. 1872. Histoire Naturelle des Insectes. Genera des Coléoptères, ou exposé méthodique et critique de tous les genres proposés jusqu'ici dans cet ordre d'insectes. Paris, Librairie Encyclopédique de Roret, 9: 411-930.

Monné, M. A. 2005. Catalogue of the Cerambycidae (Coleoptera) of the Neotropical Region. Part II. Subfamily Lamiinae. Zootaxa 1023: $1-759$

Thomson, J. 1864. Systema cerambycidarum ou exposé de tous les genres compris dans la famille des cérambycides et familles limitrophes. Mémoires de la Société Royale des Sciences de Liège 19: 1-540.

Tippmann, F. F. 1960. Studien über neotropische Longicornier III (Coleoptera, Cerambycidae). Koleopterologische Rundschau 37-38: $82-217$.

Recebido em 13/07/2007; aceito em 08/01/2008 